\title{
Imaging Description of Extragenital Müllerian Adenosarcoma: A Case Report
}

\section{Descrição da imagem do adenosarcoma mülleriano extragenital: relato de caso}

\author{
Annalisa Mone ${ }^{10}$ Piergiorgio lannone ${ }^{2}$ \\ ${ }^{1}$ Department of Radiology, University of Verona, Verona, Italy \\ 2 Section of Obstetrics and Gynecology, Department of Morphology, \\ Surgery and Experimental Medicine, University of Ferrara, Ferrara, Italy \\ Address for correspondence Annalisa Mone, MD, Reparto di \\ Radiologia, Policlinico G.B. Rossi, Università Degli Studi di Verona, \\ Piazzale LA Scuro, 10, 37134, Verona, Italy \\ (e-mail: annalisa.mone@gmail.com).
}

Rev Bras Ginecol Obstet 2019;41:124-128.

\begin{abstract}
\section{Keywords}

- extragenital müllerian adenosarcoma

- computed tomography

- pelvic mass

- uterine sarcoma

\section{Resumo}

\section{Palavras-chave}

- adenosarcoma mülleriano extragenital

- tomografia computadorizada

- massa pélvica

- sarcoma uterino

Müllerian adenosarcoma is a very rare gynecological disease, comprising $5 \%$ of uterine sarcomas. Extragenital localizations are even rarer. We report a very interesting case of a 27-year-old woman complaining of pelvic pain, with a subsequent diagnosis of extragenital Müllerian adenosarcoma. This is the first case reported in the literature with a complete and wide imaging description. Even if rare, Müllerian adenosarcoma should be hypothesized in case of young female patients presenting with suspicious pelvic mass.

O adenosarcoma Mülleriano é uma doença ginecológica muito rara, compreendendo $5 \%$ dos sarcomas uterinos. Localizações extragenitais são ainda mais raras. Relatamos um caso muito interessante de uma mulher de 27 anos queixando-se de dor pélvica com diagnóstico subsequente de adenosarcoma Mülleriano extragenital. Este é o primeiro caso relatado na literatura com uma descrição completa e ampla de imagem. Mesmo que raro, o adenosarcoma Mülleriano deve ser hipotetizado no caso de pacientes jovens do sexo feminino com massa pélvica suspeita.
\end{abstract}

\section{Introduction}

Müllerian adenosarcoma is an uncommon variant of the Müllerian mixed tumor of the uterus. ${ }^{1}$ Uterine adenosarcomas make up $5 \%$ of all uterine sarcomas and tend to occur in postmenopausal women but may also be diagnosed in adolescents and young women. ${ }^{2}$ The uterus is the most common site

(1D)Annalisa Mone's ORCID is http://orcid.org/0000-0002-5642-7148. of origin, but, even though rarer, it may also arise in extrauterine locations, including the ovary, vagina, fallopian tube, gastrointestinal tract, bladder and peritoneal sites, such as the pouch of Douglas and the intestinal serosa. ${ }^{3-5}$ There are no specific risks or etiologic factors, but extrauterine adenosarcoma has been reported to arise in association with endometriosis. ${ }^{6}$ There are also few cases of adenosarcoma arising in women on tamoxifen, and those with endogenous hyperestrogenism or prior pelvic radiation. ${ }^{7-9}$ Adenosarcoma is characterized by a biphasic

Copyright $\odot 2019$ by Thieme Revinter Publicações Ltda, Rio de Janeiro, Brazil

License terms
August 28, 2018

accepted

10.1055/s-0038-1676110. ISSN 0100-7203. 
cellular differentiation, its essential features include benign appearing epithelial component and malignant mesenchymal component. ${ }^{3,4,10,11}$ The epithelial component is usually characterized by endometrioid type; the malignant stromal component is typically low grade. ${ }^{3,6}$ The most common symptom of uterine adenosarcoma is vaginal bleeding; some patients complain of pelvic pain, vaginal discharge or symptoms related to uterine enlargement. ${ }^{9}$ Upon examination, the patients often have a polypoid mass protruding through a dilated cervical os. ${ }^{6}$ Extrauterine adenosarcomas have no specific clinical presentation: abdominal discomfort is the most common symptom. ${ }^{3,6,12}$ Müllerian adenosarcomas have a good prognosis, with the exception of deeply invasive tumors or those with high grade sarcomatous overgrowth; extrauterine adenosarcomas also have a higher risk of recurrence. ${ }^{9}$ Risk factors associated with recurrence and metastases include deep myometrial or lymph-vascular space invasion and sarcomatous overgrowth. ${ }^{6,10}$ We report a very interesting case of extrauterine Müllerian adenosarcoma demonstrated on ultrasound and computer tomography (CT) imaging. According to our knowledge, this is the first case described in the literature of extragenital Müllerian adenosarcoma with full and exhaustive images not associated with known risk factors and/or comorbidities.

\section{Case Description}

A 27-year-old woman refers to our hospital complaining of dyspepsia and abdominal distension for a few months. Her past medical history is silent. Her blood exams show an elevated CA 125 of 1,309 UI/ml. Upon physical examination, she presents considerable abdominal distension and obtuseness to the lower abdominal quadrants as for the presence of ascites. A transabdominal ultrasound, performed using a Philips C5-2 MHz USB curved array transducer (Philips Healthcare, Best, Netherlands) confirms the ascites in all peritoneal recesses ( - Fig. 1A) and reveals a bulky mass, which occupies almost entirely the abdominal cavity and the pelvis. It appears predominantly solid, with few cystic components and heterogeneous echotexture (-Fig. 2A). Internal blood flow is demonstrated on ultrasound color Doppler (-Fig. 3A). A 246-
CT (Philips Healthcare, Best, Netherlands) of the abdomen and pelvis is performed after a few hours for further evaluation. The protocol used is as follows: precontrast phase and postcontrast tri-phase scan (arterial phase, portal/venous phase and delayed phase). The CT confirms the findings highlighted on the ultrasound: diffused ascites (-Fig. 1B) and a multiloculated, voluminous solid mass with definite margins measuring $20 \times 10 \mathrm{~cm}$ on the axial view, with cranio-caudal extension of $23 \mathrm{~cm}$. The mass occupies partially the abdomen and entirely the pelvis, and presents contextual cystic components, the largest of which was $6 \times 4 \mathrm{~cm}$, and calcifications, the largest of which measured $14 \mathrm{~mm}$ (-Fig. 2B-C). It shows heterogeneous vascularity during the arterial phase ( $\mathbf{F i g}$. 3B-C) and presents few septa and pseudosepta, which have a lively enhancement on postcontrast images, especially during the portal/venous phase (-Fig. 3D). The mass dislocates the intestinal loops but does not show signs of local invasion. There are no enlarged lymphnodes. The uterus is normal; the ovaries are not viewable. The patient undergoes surgery with the presumed diagnosis of an adnexal cancer. The mass is described as $30 \mathrm{~cm}$ in size, with irregular surface and cerebroid appearance. The uterus and the ovaries are normal. Intraoperative pathological consultation reveals borderline tumor of the fallopian tube. Bilateral salpingectomy and total omentectomy are performed. The definitive histological examination shows normal fallopian tubes and Müllerian adenosarcoma arising from the peritoneum. The peritoneal fluid presents no pathological features. The patient is discharged without medical therapy and the hospital stay is uneventful. One month after the surgery, hysteroscopy is performed to obtain endometrial sample, which results negative for neoplasia. Two months after the surgery, the patient undergoes a whole-body CT scan, which shows neither signs of recurrence nor metastasis.

\section{Discussion}

Müllerian adenosarcoma is a very rare tumor and comprises only $5 \%$ of uterine sarcomas, occurring in patients from 14 to 89 years old (median 58).,9 The extragenital locations are even rarer, and usually the patients affected by this pathology present a history of endometriosis, tamoxifen therapy,
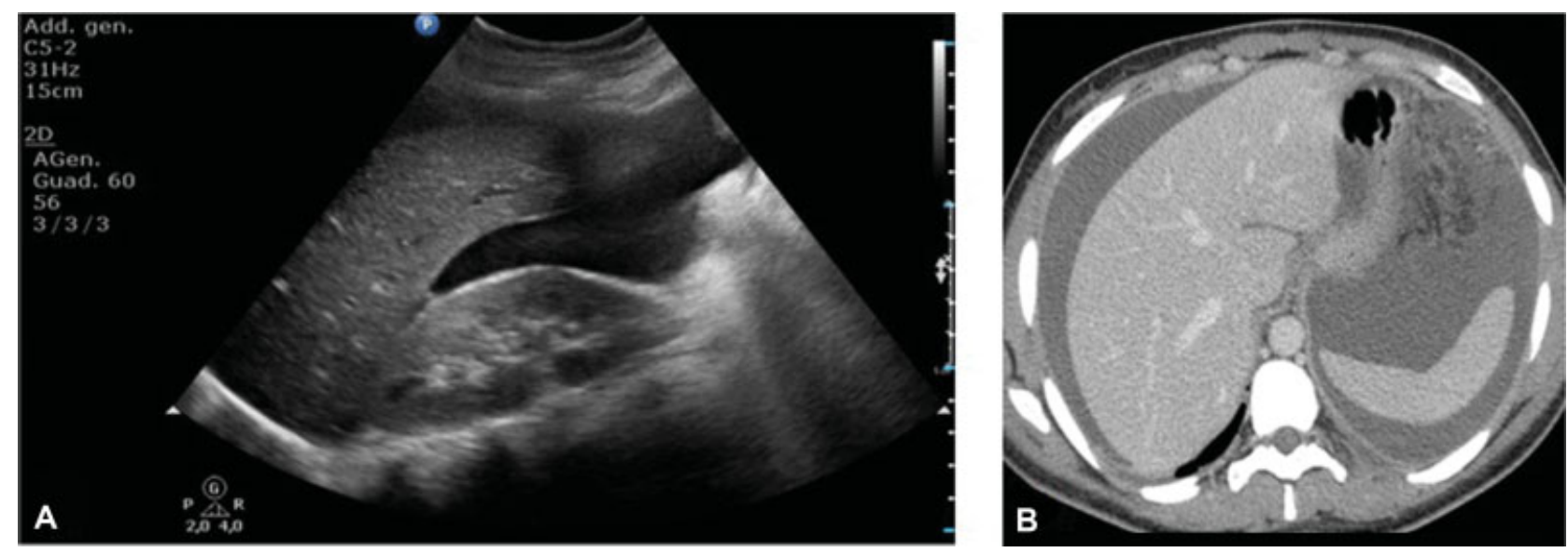

Fig. 1 Copious ascites on transabdominal ultrasound (A) and CECT (B). 

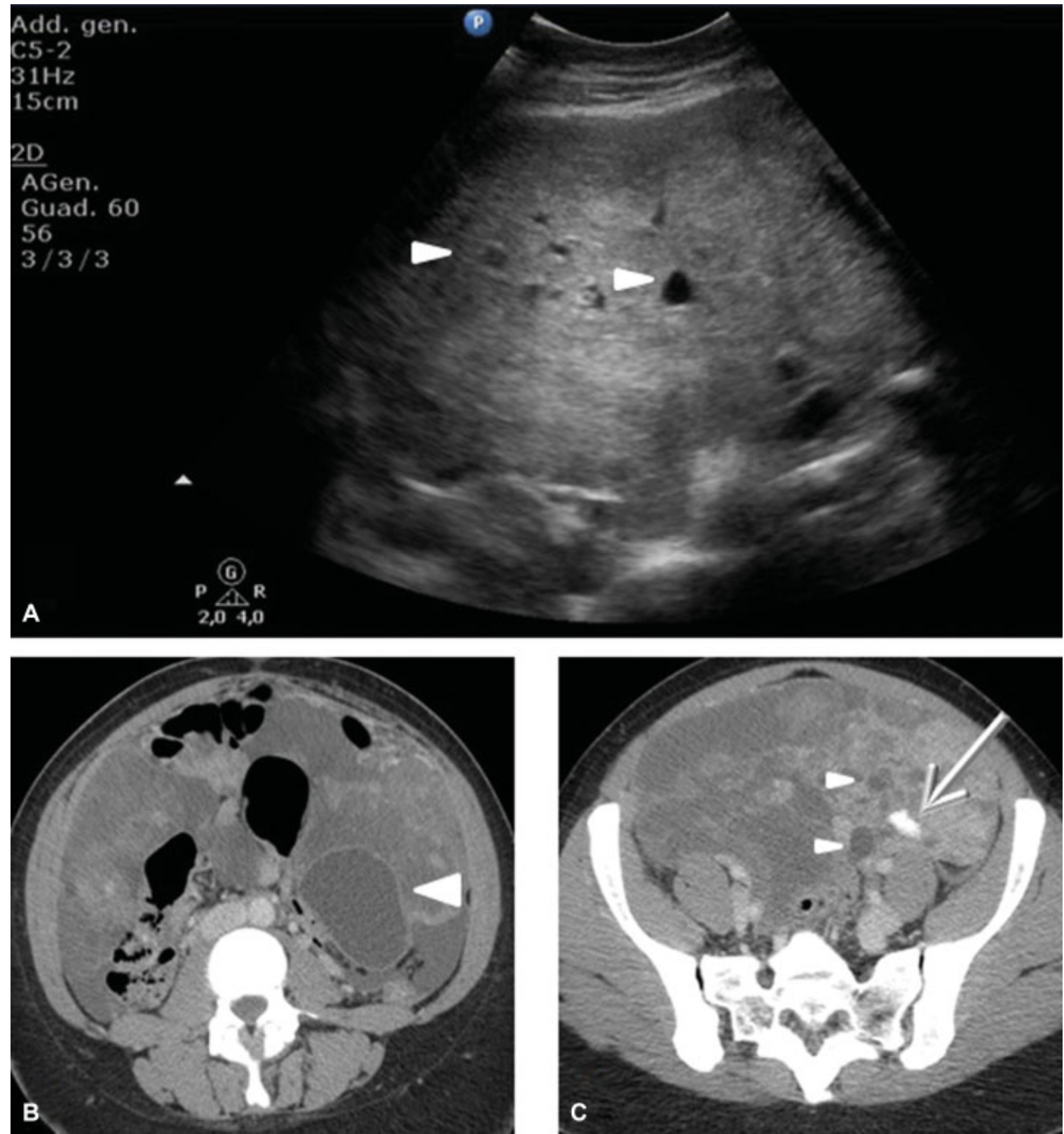

Fig. 2 Transabdominal ultrasound (A) and axial CECT (B-C) images show a large solid, heterogeneous mass containing cystic spaces ( $\mathbf{(})$. Note the presence of calcifications $(\rightarrow)(C)$.

hyperestrogenism or prior pelvic radiation. ${ }^{9}$ Other patients may have a history of recurrent endometrial or cervical polyps; however, these may be coincidental associations without proven etiological factors. ${ }^{6,9}$ In the literature, among the risk factors described, the majority of adenosarcomas are associated with endometriosis. ${ }^{13-24}$ Symptoms may vary according to location. In uterine adenosarcoma, the most common presenting symptom is abnormal vaginal bleeding, but some patients present pelvic pain, abdominal mass or vaginal discharge. ${ }^{9}$ In the extragenital locations, abdominal discomfort is the usual presenting symptom. ${ }^{6}$ Histologically, the tumor is characterized by the presence of both epithelial and stromal elements, with the latter predominating. ${ }^{9}$ The epithelial elements usually consist of glands and, in most cases, the epithelium is endometrioid and resembles prolif- erative endometrium; on the other hand, the malignant stromal component is typical low grade. ${ }^{6,9}$ Mesenchymal elements may also be observed. ${ }^{9}$ Adenosarcomas with more than $25 \%$ of the tumor composed of pure high-grade sarcoma are designated as adenosarcomas with sarcomatous overgrowth, and they may be associated with deep myometrial and vascular invasion. ${ }^{6}$

In most adenosarcomas with a low-grade stromal component, the stromal element expresses estrogen receptor, progesterone receptor, CD10, WT1, smooth muscle actin, low MIB1 proliferation index and is negative for P53. ${ }^{6,9}$ The CD10 is diagnostically a useful marker for endometrial stromal tumors and can also be used in establishing the diagnosis of uterine adenosarcomas. ${ }^{6}$ Alterations in the PIK3CA/AKT/ PTEN pathway were also found. ${ }^{9}$ Immunohistochemistry of 

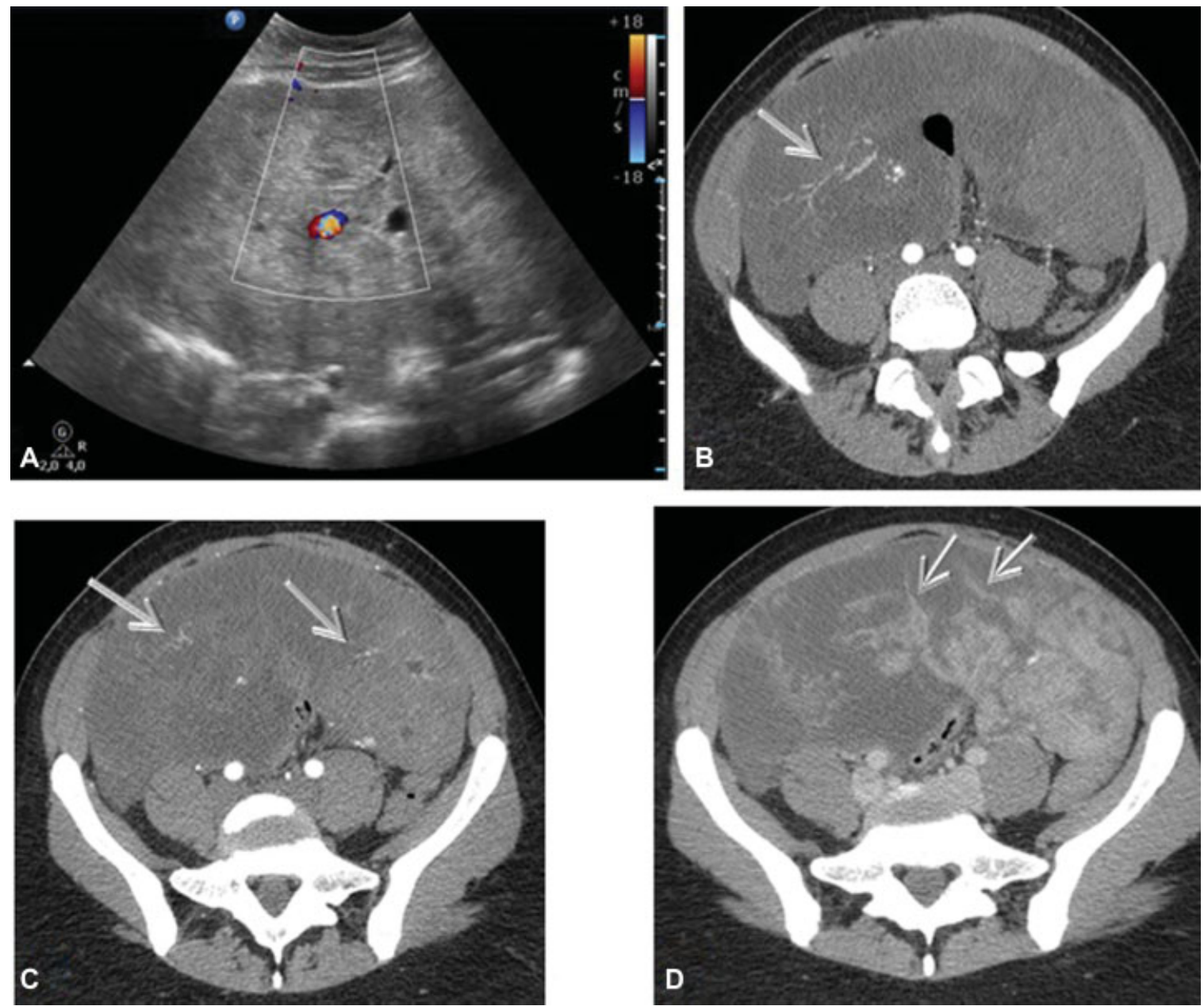

Fig. 3 Mass shows internal vascularity on ultrasound color Doppler (A) and axial computed tomography during arterial phase $($ B-C) $(\rightarrow)$. Enhancing on venous/portal phase of septa and pseudosepta (D) $(\rightarrow)$.

our patient presented high level of estrogen/progesterone receptors, smooth muscle actin positivity and low MIB 1 proliferation index. Outside the uterine cavity, the main locations of the cancer described are the ovary, peritoneum, pelvis and, in patients who underwent hysterectomy, the vagina. ${ }^{14,17-25}$ Other sites where extragenital Müllerian adenosarcoma may be found are the rectum and vaginalrectum septum. ${ }^{13,15,16}$ In 2001, Hirakawa et $\mathrm{al}^{24}$ have interestingly reported for the first time the presence of tumor cells in the ascitic fluid in a patient presenting adenosarcoma of the ovary. ${ }^{24}$ In our patient, the peritoneal fluid presented no pathological cells. Only in one case, it was described that a patient with history of endometriosis presented with extragenital adenosarcoma and concomitant colon-rectal neoplasm, but the association between the two tumors has not been studied yet. ${ }^{15}$ Patients with Müllerian adenosarcoma have a generally good prognosis, unless the tumor shows deep myometrial invasion or sarcomatous overgrowth. ${ }^{9}$ Among the cases present in the literature, only a few have been reported with a histologic description of "sarcomatous overgrowth," a very rare condition with a worse prognosis. ${ }^{18,21,23}$ Recurrences, which occur in 20 to $30 \%$ of patients, are usually confined to the vagina, pelvis or abdomen (44\% recurrence rate of adenosarcomas with sar- comatous overgrowth compared with $14 \%$ without sarcomatous overgrowth). ${ }^{6,9}$ Anyway, long term follow-up is needed. ${ }^{9}$ The treatment of uterine adenosarcoma is hysterectomy with bilateral salpingo-oophorectomy; however, ovarian preservation can be considered in premenopausal women; treatment decisions need to be individualized based on age and clinical/pathological parameters. ${ }^{6}$ This is the first case reported in the literature, with a wide and complete imaging description of this lesion, in a patient with a silent medical history, without known risk factors and/or comorbidities, such as endometriosis. Interestingly, this is the second case reported in Italy. ${ }^{16}$

\section{Conclusion}

Müllerian adenosarcoma should be included in the differential diagnosis of young patients presenting with complex masses in. Although Müllerian adenosarcoma is a very rare disease, more studies are needed to improve the knowledge of this condition to provide its diagnostic, clinical and therapeutic management.

Conflicts of Interest

None to declare. 


\section{References}

1 Guidozzi F, Smith T, Koller AB, Reinecke L. Management of uterine Müllerian adenosarcoma with extrauterine metastatic deposits. Gynecol Oncol 2000;77(03):464-466

2 Abeler VM, Røyne O, Thoresen S, Danielsen HE, Nesland JM, Kristensen GB. Uterine sarcomas in Norway. A histopathological and prognostic survey of a total population from 1970 to 2000 including 419 patients. Histopathology 2009;54(03):355-364 Doi: $10.1111 / \mathrm{j} .1365-2559.2009 .03231 . x$

3 McCluggage WG. Mullerian adenosarcoma of the female genital tract. Adv Anat Pathol 2010;17(02):122-129 Doi: 10.1097/ PAP.0b013e3181cfe732

4 D'Angelo E, Prat J. Uterine sarcomas: a review. Gynecol Oncol 2010;116(01):131-139 Doi: 10.1016/j.ygyno.2009.09.023

5 Patrelli TS, Gizzo S, Di Gangi S, Guidi G, Rondinelli M, Nardelli GB. Cervical Mullerian adenosarcoma with heterologous sarcomatous overgrowth: a fourth case and review of literature. BMC Cancer 2011;11:236 Doi: 10.1186/1471-2407-11-236

6 Friedlander ML, Covens A, Glasspool RM, et al. Gynecologic Cancer InterGroup (GCIG) consensus review for mullerian adenosarcoma of the female genital tract. Int J Gynecol Cancer 2014;24(09, Suppl 3):S78-S82 Doi: 10.1097/IGC.0000000000000239

7 Akhavan A, Akhavan Tafti M, Aghili F, Navabii H. Uterine adenosarcoma in a patient with history of breast cancer and long-term tamoxifen consumption. BMJ Case Rep 2012;2012:bcr2012006590 Doi: $10.1136 /$ bcr-2012-006590

8 Press MF, Scully RE. Endometrial "sarcomas" complicating ovarian thecoma, polycystic ovarian disease and estrogen therapy. Gynecol Oncol 1985;21(02):135-154 Doi: 10.1016/0090-8258(85) 90246-X

9 McCluggage WG. A practical approach to the diagnosis of mixed epithelial and mesenchymal tumours of the uterus. Mod Pathol 2016;29(Suppl 1):S78-S91 Doi: 10.1038/modpathol.2015.137

10 Clement PB, Scully RE. Mullerian adenosarcoma of the uterus: a clinicopathologic analysis of 100 cases with a review of the literature. Hum Pathol 1990;21(04):363-381

11 Clement PB, Scully RE. Uterine tumors with mixed epithelial and mesenchymal elements. Semin Diagn Pathol 1988;5(02):199-222

12 Huang GS, Arend RC, Sakaris A, Hebert TM, Goldberg GL. Extragenital adenosarcoma: a case report, review of the literature, and management discussion. Gynecol Oncol 2009;115(03):472-475 Doi: 10.1016/j.ygyno.2009.07.033

13 Yang C, Oh HK, Kim D. Müllerian adenosarcoma arising from rectal endometriosis. Ann Coloproctol 2014;30(05):232-236 Doi: 10.3393/ac.2014.30.5.232
14 Kar R, Verma SK, Papa D, Sylvia MT. Extrauterine adenosarcoma arising in omental endometriosis: rare site of occurrence of a rare tumor. Indian J Pathol Microbiol 2014;57(04):640-641 Doi: 10.4103/0377-4929.142720

15 Chang HY, Changchien CC, Chen HH, Lin H, Huang CC. Extrauterine müllerian adenosarcoma associated with endometriosis and rectal villotubular adenoma: report of a case and review of the literature. Int J Gynecol Cancer 2005;15(02):361-365 Doi: 10.1111/j.1525-1438.2005.15230.x

16 Raffaelli R, Piazzola E, Zanconato G, Fedele L. A rare case of extrauterine adenosarcoma arising in endometriosis of the rectovaginal septum. Fertil Steril 2004;81(04):1142-1144 Doi: 10.1016/j.fertnstert.2003.09.053

17 Liu L, Davidson S, Singh M. Müllerian adenosarcoma of vagina arising in persistent endometriosis: report of a case and review of the literature. Gynecol Oncol 2003;90(02):486-490 Doi: 10.1016/ S0090-8258(03)00266-X

18 Murugasu A, Miller J, Proietto A, Millar E. Extragenital mullerian adenosarcoma with sarcomatous overgrowth arising in an endometriotic cyst in the pouch of Douglas. Int J Gynecol Cancer 2003; 13(03):371-375

19 Judson PL, Temple AM, Fowler WC Jr, Novotny DB, Funkhouser WK Jr. Vaginal adenosarcoma arising from endometriosis. Gynecol Oncol 2000;76(01):123-125 Doi: 10.1006/gyno.1999.5617

20 Fukunaga M, Ishihara A, Ushigome S. Extrauterine low-grade endometrial stromal sarcoma: report of three cases. Pathol Int 1998;48(04):297-302 Doi: 10.1111/j.1440-1827.1998.tb03909.x

21 Kumar S, Raza M, Tariq MU. Low grade Mullerian adenosarcoma of pouch of Douglas recurring as bilateral ovarian high grade Mullerian adenosarcoma with rhabdomyosarcomatous overgrowth after 11 years. J Pak Med Assoc 2018;68(08):1263-1266

22 Shetty M, Lal N, Vu NH. Müllerian adenosarcoma of the ovary: case report and review of the literature. Ultrasound Q 2007;23 (03):189-191 Doi: 10.1097/RUQ.0b013e31814b94f7

23 Kanngurn S, Somran J, Art-Ong C, Lamlertthon W, Porncharoenpong S. Primary peritoneal adenosarcoma with stromal overgrowth and fetal type cartilage: a case report and literature review. J Med Assoc Thai 2005;88(06):849-854

24 Hirakawa E, Kobayashi S, Miki H, et al. Ascitic fluid cytology of adenosarcoma of the ovary: a case report. Diagn Cytopathol 2001; 24(05):343-346 Doi: 10.1002/dc.1074

25 Kato N, Zhe J, Endoh Y, Motoyama T. Extrauterine Müllerian adenosarcoma of the peritoneum with an extensive rhabdomyosarcomatous element and a marked myxoid change. Pathol Int 2000;50(04):347-351 Doi: 10.1046/j.1440-1827.2000.01039.x 